\title{
A performance index of football teams: the Spanish case
}

Jose Maria Fernandez-Crehuet, Jorge Rosales-Salas \& Pablo Navarro

To cite this article: Jose Maria Fernandez-Crehuet, Jorge Rosales-Salas \& Pablo Navarro (2019): A performance index of football teams: the Spanish case, Sport in Society, DOI: 10.1080/17430437.2019.1621841

To link to this article: https://doi.org/10.1080/17430437.2019.1621841 


\title{
A performance index of football teams: the Spanish case
}

\author{
Jose Maria Fernandez-Crehuet ${ }^{\mathrm{a}}$, Jorge Rosales-Salas ${ }^{\mathrm{b}}$ and Pablo Navarro ${ }^{\mathrm{a}}$ \\ aniversidad Politécnica de Madrid, Madrid, Spain; 'bentro de Economía y Políticas Sociales, \\ Universidad Mayor, Santiago, Chile
}

\begin{abstract}
In this article, we propose an index to measure the performance of the Spanish Football league most important teams during the 2016/2017 season. Using data from 10 Spanish first division football clubs, and principal components analysis, we construct a performance index as a combination of five dimensions: economic, fans-related, historical, team quality and the season's data, along with 22 variables. Results show that Real Madrid, FC Barcelona and Athletic de Madrid are the highest-ranked teams, matching their season's top positions. Additionally, while Sevilla, Villarreal, Real Sociedad and Espanyol exceeded expectations, Athletic de Bilbao, Valencia and Real Betis did not meet their own, compared with their season's position. This Performance Index of Football Teams could assist club's decisions designed to improve their performance in different dimensions.
\end{abstract}

\section{KEYWORDS}

Football performance index; Spanish football; principal component analysis

\section{Introduction}

During the last decades, the conception of sport as a fun and healthy activity framed within the leisure economy has undergone a radical change to become the spectacle we know today, a business and a social event capable of attracting the interest of millions of people around the world. Therefore, the main leagues of professional football - mostly European - have undergone important changes in their business model. Over the years, they have adapted to current needs and have moved the competition from the sports field to the economic, in a context in which economic resources are increasingly important to maintain the intensity of competitions, the sporting success of clubs and the interest of fans. Football is not only a game; it constitutes a total social event, since by analyzing all of its components (playful, social, economic, political, cultural and technological), one can better decipher our contemporary societies, better identify our fundamental values and the contradictions that make up our world (Hernández 2006).

The clubs of the main leagues of football, and among them those of the National League of Professional Football in Spain (LaLiga), have suffered a strong transformation from being sports clubs that looked for means of financing their activity to become companies based

CONTACT Jorge Rosales-Salas @ jorge.rosales@umayor.cl

This article was partially written while Jose Maria Fernandez-Crehuet was Visiting Fellow at Harvard University, to which he would like to express his thanks for the hospitality and facilities provided. 
on the sporting event as a product, significantly increasing the ways to obtain its revenues. National professional football championships represent a high impact economic activity that moves billions of euros annually, and therefore, contribute significantly to the gross domestic product of any country. In addition, they represent an important source of employment for thousands of people, acting as a driving force in the economy (Cano 2015).

This study arises from the interest to analyze the current situation of football and the results obtained by the most important teams of the Spanish League. Over the last years, we have seen very positive results by clubs that do not stand out for the quality of their team or economic potential. A clear example is the league win by Atlético de Madrid on the 2013/2014 season and its last results in the Champions League, the rise of Monaco on the 2016/2017 season of the French league, or the amazing conquest of the English league by Leicester City on the 2015/2016 season, team that ascended the same year to the maximum category of the English football. Modern football has changed and although it still depends heavily on the football conditions of the best soccer players on the planet or the ability of the teams to spend money to incorporate the most talented, these are not the only factors that influence the performance and results obtained by football clubs.

In this article, we propose an index to analyze the clubs' performance as a combination 22 variables in five dimensions: (i) economic, (ii) fans-related, (iii) historical, (iv) team's quality and (v) season's data. We analyze information from the most important teams in the history of Spanish football. The study focuses on the performance of the following teams during the 2016/2017 season, following the historical classification of the competition: Real Madrid, Barcelona, Atletico de Madrid, Sevilla, Valencia, Athletic de Bilbao, Villarreal, Real Sociedad, Betis and Espanyol. We leave out the rest of the teams that were part of the first division due to, among other reasons, the similarity in the data of the indicators and the little relevance they provide, given their poor historic performance and the fact that they have alternated between first and second division.

The remainder of this article is organized as follows. In the next section we describe the background used for the inclusion of the five dimensions of the performance index. Later, we present the materials and methods used to compute the index. The next section describes the main results and discussion and finally, the last section concludes the article.

\section{Background}

This performance index is a specific tool for documenting and analyzing the multidimensional nature of the factors than potentially influence the club's performance within the league. The underlying nature of the index considers that performance in the Spanish National Football League is a broader concept than simply hiring the best players and addresses the different layers of causes for a team's success. Hence, our analysis examines the relationship between several measures.

The first dimension of indicators refers to the economic characteristics of each club, fundamental aspect when arming the teams and the clubs' spending possibilities. The following indicators will be studied within this dimension: club's income, television rights, expenses and available budget.

Within the first dimension, we start by incorporating the income/revenues of each club. Most research into economic and financial features of football analyze the relationship between sports performance and income, expecting them to be positive (Szymanski and 
Kuypers 1999; Barajas et al. 2005; Gómez and Opazo 2007). Furthermore, the influence of television distribution is especially important on the results of a club during a season. Broadcasting networks are going to negotiate a higher amount of money with the clubs that will provide the most benefits, because of the importance of these clubs in the world of football, leaving little to negotiate for the remaining clubs in the league. The expenses that each club can allow influence the performance they get, and it seems clear that the more money a club can spend the better results it should get, since it allows it to have better players and technical staff (Busto 2014). Accordingly, a variable that cannot be ignored in this first dimension is budget. This can be considered a quality indicator of the club's group of players, because it is related to their salaries.

The second dimension refers to the support that the fans give to the club, both directly and indirectly. Here we consider the number of subscribers that each club has, the average attendance during the season, the fan-base living in the city and income per capita.

In this study, we measure this dimension in terms of the number of subscribers that the clubs have, understanding that the greater the number of subscribers, the better results should obtain a football team throughout the season (Di Betta and Amenta 2010). Additionally, we use the average attendance to the stadiums during the 2016/2017 season as an influential indicator in performance, considering research that categorizes this aspect as an influence over the confidence of the players (Gonzalez-Gomez and Picazo-Tadeo 2009). As stated by Buraimo and Simmons (2009), the results of a football team can also be influenced by the people who live in the city and the possibilities that these people have to access the football show and accompany the team. Christina, Barresi, and Shaffner (1990) and Boscá et al. (2009) concluded that the geographical location affects the performance and effectiveness of companies and football teams. In Spain, the existing regionalism generates a greater sense of belonging to their respective clubs (Ballesteros 2015).

The third dimension deals with the history of each team, since the achievements to date can be a good indicator of future performance. The variables used are: the age of the club, the percentage of matches won in the First Division, and the ratio of league titles in relation to the years of existence.

According to Barajas (2004), the seniority of a football club is very relevant when it comes to the results that occur in the seasons. The number of played matches represents the sporting experience because the years within the category measured with this figure are an important benchmark for determining the prestige of a club, in order to get contracts with sponsors and better television revenues, or to have a knowledge of how to make better sport and economic decisions within the season. According to a study conducted by Barros and Leach (2006), the most played clubs in a certain competition are the ones that should get better sporting results, so it seems logical that if a football team has played a very large number of matches in the First Division, it should be able to take advantage of that experience to excel. The status that a football team obtains depends largely on the sporting results obtained, but also it depends on the matches that won throughout its history (Barajas 2004). As a final indicator of this group, we considered the number of titles obtained in the competition according to the years that the club has, following Busto (2014). It seems reasonable to think that the sporting successes achieved in the competition throughout history are related to the results that the team obtains in the present (Barajas and Crolley 2009).

As a fourth dimension we considered the quality that each club has in terms of a series of variables: the coach's influence measured by his salary, the coach's experience measured 
by titles won, the importance of having a good medical and physical team measured by season's injuries, the average salary of each staff member, the average age of the players, the number of players who are called to their nation's team, and the importance of the players quarry.

To begin, in this dimension we first considered the coach. It is generally correlated that the higher that salary is, the better the coach's skills and the coach will be able to achieve success and get good results (Gonzalez-Gomez and Picazo-Tadeo 2009). The coach's experience is another factor to consider, measured as the titles per year he has achieved in his career (Audas, Dobson, and Goddard 2002; Busto 2014). The third indicator is the influence that doctors and the physical preparers have on the team. The variable is the number of times that players have lost a match by injury (Soriano 2005). According to the sports theory of the main European leagues, the sporting results of a football team depend on the quantity paid to the players who make up the team (Rendón 2012). Additionally, the age of the players also reflects the chances of the club's success (Audas, Dobson and Goddard 2002). However, the experience of older players due to the years they carry in the profession and the teams in which they have been makes the combination with younger players better to lead the team to greater sporting successes. Furthermore, if a team has more players who also compete with the country's selections, it should get better results as these players are of higher quality than those who do not enjoy playing with their respective countries (Busto 2014). Finally, Lledó and Huertas (2012) concluded that the more investment exists in the quarry and the more footballers of it are playing in teams of the first level, the better should be the performance of the clubs.

The fifth and final dimension incorporates the season's data: the influence of penalties incurred by each team, Union of European Football Associations (UEFA) points accumulated, television audiences and player's fatigue measured by the kilometres travelled during the season to play as visitors.

The first indicator of the results dimension of the season is the influence of penalties. According to some studies (Reina-Gomez and Hernández-Mendo 2012), if a team has suffered more penalties over the course of a season it will have as a result that the football performance will be lower. The UEFA coefficients are statistics produced periodically by the UEFA, which are used to order the teams to carry out the draws of the two major continental competitions, the Champions League and the Europe League (Gómez, Gòmez, and Jimenez 2013). The greater the number of points any team has in this ranking, the better is the performance trend in the short term (Jiménez 2013). In recent years, the number of televised matches in Spain has significantly increased, and according to research, the performance of a club in football terms is related to television audiences (Marcos 2016). Finally, the distance travelled by the players to games is a relevant data to verify if it actually has an impact on the results of the team, being these worse the greater the distance travelled. In a recent study (Ceballos-Cún 2017) on the performance of the Spanish teams in the season $2016 / 2017$, results show that the teams that travelled the most distance were the one that had the least games won far from their stadium, and suffered the most defeats.

\section{Material and methods}

The data is shown in Table 1 (LaLiga 2017), as obtained from the official website of the Spanish Professional Football League. 


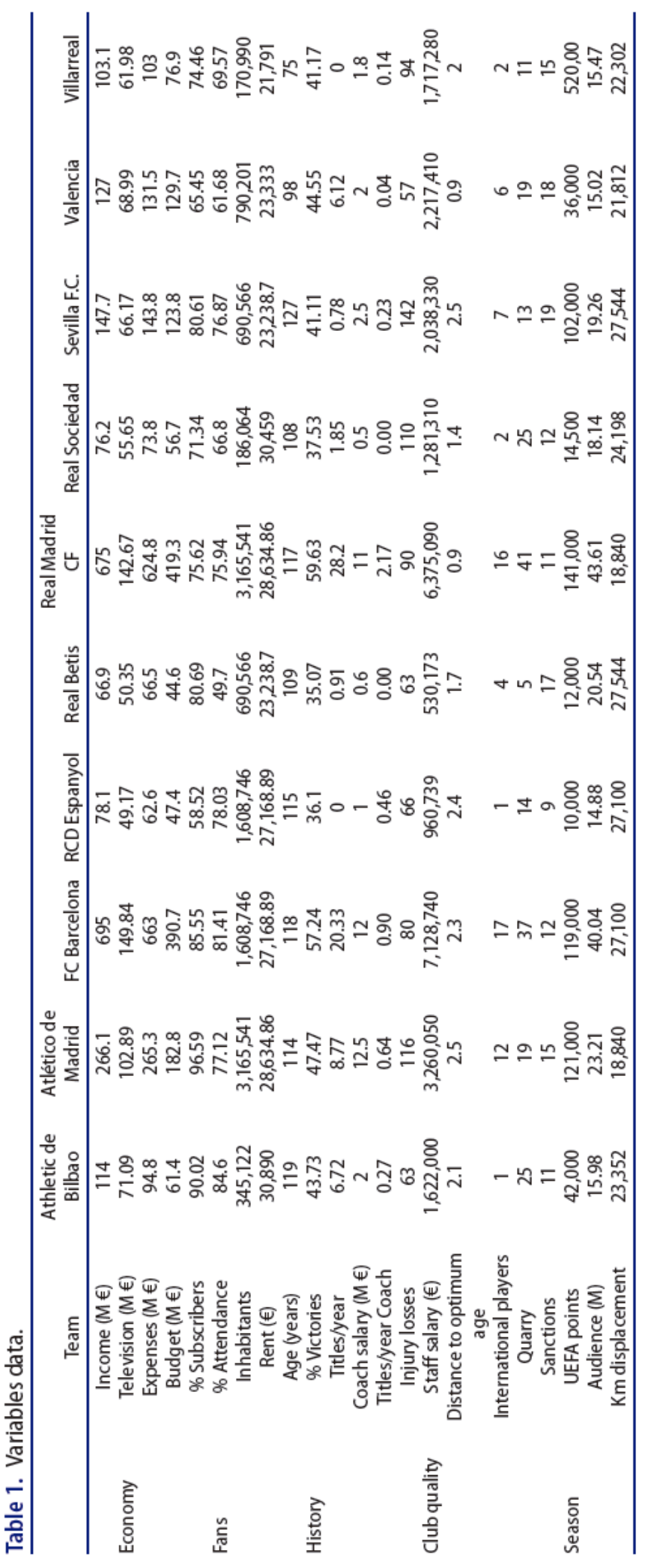




\section{Economy}

In terms of income, the most influential teams, both at European and global level, are Real Madrid and Barcelona; however, Atlético de Madrid has done very good seasons both in domestic competition and in the European Cup, so it stands out against other Spanish clubs (Pérez-González 2017). Thanks to the successes achieved both in the present and in the close past, these clubs nourish themselves of sponsors to obtain a high amount of advertising revenues and with them to continue getting titles, because with money everything is easier (Robles 2015). The two Spanish soccer giants, Real Madrid and Barcelona, make up more than half of the season's earnings. Between these two teams the money earned is greater than the eight remaining teams on this study.

Television companies are going to negotiate a higher amount of money with the clubs that will provide the most benefits, such as Real Madrid and Barcelona, because of the importance of these clubs in the world of football, leaving just a little margin to negotiate for the remaining First Division clubs. As a result, it seems clear that if football results depended of television distribution, the best results should be from these two teams (Gómez and Opazo 2007). For example, from first division in the 2016/2017 season, FC Barcelona had a revenue of over 146 million euros from television rights, followed by Real Madrid C.F. and Club Atlético de Madrid with 140.1 million euros and 99.2 million euros respectively (Statista 2019).

The spending capacity of the clubs under study is very uneven; however, measures have been taken by the Spanish league and thanks to expenditure control, this situation has been slightly improved. The control has focused especially on the aspect of salaries; this way the clubs are aware of the money they can use in signing to form the staff. In addition, clubs that fail to comply with this control face sanctions that end with the prohibition of signing and can even lead to the downgrade. For both income and expenses, the league has a database with the movements that are produced of money to control the accounts of the teams, being obliged to inform at the time that any income or expense occurs (Escondrillas 2016). As well as it happened with income, the two most powerful teams are allowed the luxury of spending more than the sum of the other clubs under study, which makes the competitive advantages of these teams far superior.

In each season, the clubs elaborate budgets according to their economic possibilities and their sporting objectives, clearly prevailing the latter. To do this, they can invest the benefits that they have collected in the previous season in new footballers in order to be able to achieve sporting success. If this premise is applied, when a team is getting more benefits, it can improve its workforce for the following season. Real Madrid is the team that has the most budget, even though it was not the one with the most revenues, so it is necessary to manage income and the expenses adequately to have the best budget possible (Busto 2014).

\section{Fans}

In the first indicator of the fans dimension it is verified that there is not so much difference between the teams. Real Madrid and Barcelona alternated in the first and second position in many of the indicators analyzed so far; however, if the results depended of the subscribers that each club has, Atlético de Madrid and Athletic de Bilbao would be the winners, relegating the third and sixth place to Real Madrid and Barcelona respectively. Real Madrid, 
despite not being the most subscribed team in Spain, is the one that constantly filled its stadium in the 2016/2017 season. Results are much more equal than in other indicators under study, reducing the differences between the teams most affected by other indicators, and Real Madrid and Barcelona. The teams of Spain's capital have clear advantage over the others in terms of city dwellers and income per capita, leaving the teams that belong to smaller cities well below the rest. Despite the fact that the cities of the Basque Country do not surpass cities such as Madrid, Barcelona, Sevilla or Valencia in population, their per capita income is the highest of Spanish cities, so the teams from Bilbao and San Sebastián would lead a hypothetical classification that only depended on the income per capita indicator.

\section{History}

It is observed that Sevilla and Athletic de Bilbao should get the best results due to being the oldest. Except for the Comunidad Valenciana teams, Valencia and Villarreal, we see a small interval in terms of the age difference of the clubs, so the experience gained is a parameter in which no club is behind the others.

The percentage of victories is the most used indicator in football studies about competitive balance. Some studies concluded that the higher percentage of victories, the better position should be obtained (Boulier and Stkeler 2003). In this study, the percentage of victories of the teams is considered as the fairest possible indicator not to harm those who have played less games in the competition for having less years of history. One point to highlight is the percentage of victories presented by Villarreal, the youngest team in the competition and yet, it has been able to compete with older clubs such as Atlético de Madrid and Athletic de Bilbao.

The number of titles achieved in the history of the club is one of the indicators in which the most difference exists between the first two, Real Madrid and Barcelona, with the rest, due to the wide list of titles of these two teams on the First Division of Spanish football.

\section{Quality}

Starting with the data of the coach's salaries, it is observed that the coach from Atlético de Madrid has the highest salary, surpassing in this classification the most powerful teams in Spain, Real Madrid and Barcelona.

Talking about titles a year of the coach, it surprises in a very notorious way the coach of Real Madrid, which in two years has achieved a ratio of titles/year never before reached to date and that makes him be far above his competitors.

In the appearance of casualties produced by injury, Madrid and Barcelona are not the most favoured, being in better place Valencia and Athletic de Bilbao. Data show a big difference between the first two classified and others, in terms of average salary of their workforce.

It is interesting to notice the average salary of Valencia, a team that has received a strong foreign investment and that did not dispute European competition in the season that is being analyzed, surpassing Sevilla and Villarreal, teams that played European competition but, however, the salaries of these clubs did not reach the level of Valencia's. 
In order to consider the average age indicator of the teams in the study we use the distance from the middle ages of the teams to the appropriate age that was previously commented ( 25 years old). Valencia and Real Madrid are the best located with this regard.

Speaking of international players, it can be verified that Real Madrid, Barcelona and Atlético de Madrid have the most players to contribute to international football, and that all the teams analyzed have, at least, one player that competes for their country's selection. All football clubs that are subject of study have teams in lower categories of Spanish football.

\section{Results of the season}

The number of penalties represents the times that players have lost matches for injury, so it may be that a player repeats throughout the season. You can see that in this aspect the team that could be considered cleaner in terms of game is the RCD Espanyol, and Sevilla, the most sanctioned team, exceeds with more than twice penalties.

The existing difference in UEFA performance between Seville and Barcelona is not as significant as in other indicators; this is due to the very noticeable performances that Sevilla has had in recent years in the Europe League, getting three of the last five titles. In addition, the good performances that Atlético de Madrid has had in the last four editions of the Champions League make this club a second place. There is a great similarity between the last eight teams classified in terms of television audiences, leaving these very far from the first two, Real Madrid and Barcelona.

In what refers to distance travelled, the teams of the capital of Spain have the least distance travelled, and are those of Andalucía who have to face a greater distance when it comes to disputing games as visitors.

\section{The principal component analysis}

To elaborate the index, a principal component analysis (PCA) is used with the objective of giving a statistical weight to each variable. The validity of this method has been demonstrated on several occasions (e.g. Fernandez-Crehuet, Gimenez Nadal, and del Valle 2017; Fernandez-Crehuet, Gimenez Nadal, and Reyes Recio 2016; Jemmali and Sullivan 2014; Bellido, Gimenez Nadal, and Ortega 201 1; Krishnakumar and Nagar 2008; Lai 2003, 2000; Filmer and Pritchett 2001; Staurowsky, Parkhouse, and Sachs 1996; Inglis, Danylchuk and Pastore, 1996; Pastore and Meacci 1994). For example, Bellido, Gimenez Nadal, and Ortega (2011) used the PCA to establish an index on the satisfaction of people who do not have a job, and Fernandez-Crehuet, Gimenez Nadal, and Reyes Recio (2016) used it to build an index on the balance between working and personal life, demonstrating the great utility of this method to generate an index according to some variables.

The PCA is a statistical method that synthesizes and structures the information contained in a data matrix. The way of proceeding is to homologize this matrix to a vector space trying to find in this some axes or dimensions that, being a linear combination of the introduced variables comply with the following premises. The dimensions must not have a correlation between them, i.e. they must be linearly independent, to ensure the structuring of the initial variables. They must have a differential and well-known importance in explaining the total variance and finally, the variables should be measured on the same scale, this is that you cannot have a measured variable in euro, another in kilometres, another in number of titles 
etc. Data can be seen in Table 1, which give a view of the existing units and grouped variables. It is necessary to normalize these variables to be able to work in the right way. The normalization method used in this study is standardization, in which a $\mathrm{z}$ value of each variable is obtained, for which the average $(\mu)$ and the typical deviation of each indicator ( $\sigma)$ must be calculated, and whose value is: $z=\frac{X-\mu}{\sigma}$. The main objective of this type of analysis is to reduce the number of known variables (indicators). The components found are taken as new variables, for which a sufficient weight is chosen so that the loss of the total variance is only the suitable one, reaching in this way to the purposes of the method, which are to simplify, to reduce and structure the initial information (Colina and López Roldán 1991).

The X parameter represents the value of each variable depending on each team. There are five dimensions in the study and the next step is to choose which variables are included in the index as part of any of the five blocks, for which several criteria should be followed. A first criterion is to analyze the relationship between the variables included in each of the five dimensions. It is necessary to study the correlation between the variables of each dimension because if the variables are too correlated the weights that will be obtained to establish the index could be misleading and the results would be unstable. A second criterion for selecting the variables to be included in the index construction is the one referred to the square factor loads. Only those variables whose square factor loads have a certain value are chosen, since the variables with low factorial charges slightly influence the variance of the domain. Variables whose factor loads (obtained using the varimax rotation) are higher in absolute value than 0.40 are selected. The variables with loads lower than 0.40 are excluded from the analysis. Once you have selected the variables to be included in each dimension that will intervene in the formation of the index according to the requirements, it is necessary to assign a specific weight to each variable, which will determine the importance of the variable in the corresponding dimension.

To assign these weights there are several methods, such as numerical weighting, arithmetic weighting, geometric weighting, using expert opinion or Delphi method and the use of factorial analysis. In this study, the PCA is used to generate the corresponding index, in accordance with the methodology described in the OECD book (OECD 2008).

Several steps must be followed to build the final classification or index. For the allocation of weights to variables, first you have to select the number of components for each dimension. You can follow several criteria to select the number of components of each dimension, and some of them are the following: (1) Variables have their own associated eigenvalues bigger than one. (2) The variables contribute to the total explained variance, individually, by $>10 \%$. (3) The variables contribute cumulatively to the total variance by $>60 \%$.

Secondly, factor loads are used to assign variables to each component. The idea is to use the factor loads obtained with the PCA (using the varimax rotation) to assign the variables to the components, where the variables are assigned to each component that present a higher factor load in absolute value.

Thirdly, the weights are obtained using the factor load matrix. Following OECD (2008) indications, the factor loads obtained with the PCA analysis are transformed into their squares because the square of the loads represents the proportion of the total variance of the indicator, fact explained by the factor. Then all the factors are added to the square of each component and the factor loads are divided by that same sum. 
Lastly, the final weight of the variables that compose each dimension is assigned using the square factor loads with the appropriate scale because they have to sum the unit, and corrected using the total variation ratio that each component can explain.

\section{Results and discussion}

The method followed to elaborate the classifications is the one followed each time indexes are built according to some statistical weights obtained by the method of the PCA, and consists in multiplying the value of each variable standardized by the corresponding statistical weight, and add this multiplication with those of all the variables referred to each team in this case. In this analysis 10 teams with 22 variables are involved, so the results of each team are determined by these variables.

Real Madrid is the winner, in the theory, of the league 2016/2017, as you can see in Table 2, clearly surpassing Barcelona and Atlético de Madrid. These three teams are the only ones that have positive indexes, differentiating from the rest in relation of the dimensions and variables analyzed. Athletic de Bilbao's index is negative but of low absolute value, so it is classified in the fourth position, a fact very meritorious considering that this team only has players from the Basque Country, with the limitations that this implies. The teams from the 5 th to the 10th position are Sevilla, Valencia, Real Sociedad, Villarreal, Betis and finally, with a very negative index, Espanyol from Barcelona.

The results obtained in each dimension for each club are shown in Figure 1. There are several possible groups of teams in relation of the economy of each club. Barcelona and Real Madrid are very far from the following team classified, Atlético de Madrid, which is a little isolated in terms of competitors in this aspect, being in a good position. Sevilla, Valencia and Athletic Bilbao are teams that despite having a negative index, they have healthy accounts in recent seasons and this has allowed them to make transfers according to their economic possibilities. One of these teams, Valencia, has been favoured by the money brought by Asian investors, which has allowed it to compete with its environment. Finally, there are the most disadvantaged teams; Villarreal, Real Sociedad, Espanyol and, finally, Betis. These teams compete in economic terms in clear disadvantage with the rest of rivals. In recent seasons, the league is trying to make the income received on television more equitable among the teams to convert the league into something more entertaining.

If the classification depended solely and exclusively on the support received by the fans, the changes compared with the previous one would be significant, despite the economy and the support of the fans being correlated by $81 \%$. In addition to varying the leader, who in

Table 2. Theoretical classification.

\begin{tabular}{rll}
\hline Ranking & Team & Theoretical classification \\
\hline 1 & Real Madrid & 7.129 \\
2 & FC Barcelona & 5.447 \\
3 & Atlético de Madrid & 2.418 \\
4 & Athletic de Bilbao & -0.184 \\
5 & Sevilla & -1.648 \\
6 & Valencia & -1.955 \\
7 & Real Sociedad & -2.349 \\
8 & Villarreal & -2.610 \\
9 & Real Betis & -2.793 \\
10 & RCD Espanyol & -3.456 \\
\hline
\end{tabular}




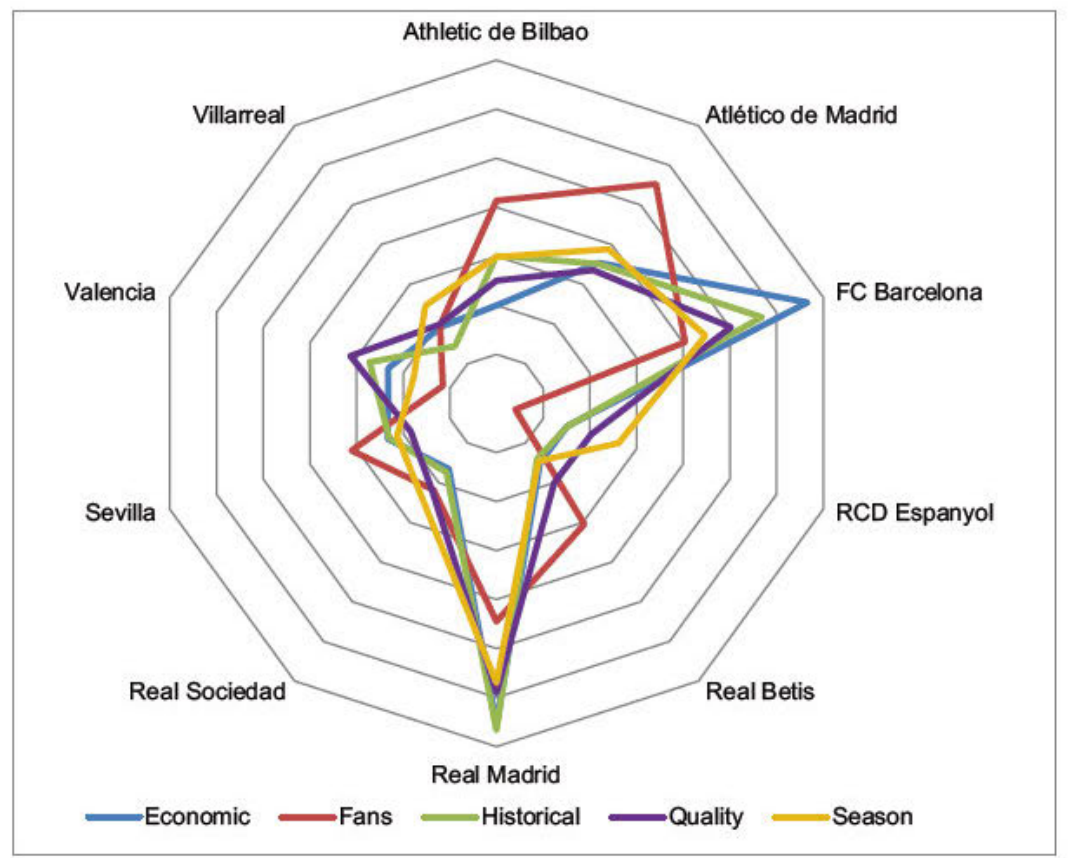

Figure 1. Dimensions comparison.

this case is Atlético de Madrid, the positions of most teams vary. Atlético de Madrid's fans are the most loyal with a negligible advantage over the second-ranked fans, Real Madrid. Real Madrid is the only team in which the economic and fans classifications coincide. The economic leader, Barcelona, descends to the fourth place if it depends on the support of his fans. Two rises with respect to economy are very notorious. One of them is Athletic de Bilbao's, team which goes from sixth to third position, and the other one is Real Betis, which goes from the last position to the sixth, showing very positively the fans aspect of these teams, because despite the economic difficulties that they have to compete with the other teams, they feel the cheers of their fans to face the good and bad times.

The history of each club cannot be changed, as opposed to having the ability to influence more on other dimensions such as economic and fans support. In the history dimension, the clear winner is Real Madrid, which has obtained numerous successes in the Spanish league since its founding. Closely following and having won numerous titles from Real Madrid in recent seasons is Barcelona, a team whose number of titles is also important.

If the first three positions are analyzed in terms of indicators referring to the quality of the club, we can see how Real Madrid snatches the first position to Barcelona, and Atlético de Madrid fulfils the expectations of quality. The indicator in which Real Madrid far exceeds its competitors is in the titles per year of his coach, because with Zinedine Zidane this team has not stopped to obtain successes since his arrival at the club. Following the fall of Sevilla already commented on the economic dimension and Villarreal from the seventh to the ninth place, the three remaining teams, Real Sociedad, Espanyol and Betis, advances two positions each, ranking in the sixth, seventh and eighth position, respectively. These teams are the ones that present average values of all the analyzed ones as far as the indicators or variables are concerned. 
In the season dimension, Real Madrid is, again, the one that leads far ahead from the second and third classified Barcelona and Atlético de Madrid, respectively. Being the leader in television audiences, having won the European Cup in three of the last four occasions and being, together with Atlético de Madrid, the team that has to travel less distance to dispute their matches as a visitor, are the reasons of the supremacy of Real Madrid in terms of data obtained from the season. It is very meritorious the fifth place obtained by Espanyol, if compared with the results that have been shown on this team in the other ratings. These good results are due to the sanctions results during the season 2016/2017, being the team less sanctioned. This fact speaks very well of the fair play that Espanyol practices against its rivals.

The results of some of the season's data are not expected for Villarreal, Sevilla and Valencia, teams whose potential suggests that they could be placed in better positions if the indicators of this dimension are considered.

The teams can analyzed in three groups; those who have exceeded expectations, those who have obtained the results that were expected according to this study and those that have not fulfilled their expectations. This can be seen in Table 3.

In the group that has exceeded the expectations the most important case is Sevilla's, team that aspired to the fifth place and to dispute the Europe League, the second continental competition, and saw like after a great season, classified fourth and was able to dispute the Champions League next season, the top continental competition. To this, it could contribute that the results obtained in season and quality dimensions were better than expected. In second place is Villarreal, who, against all odds, achieved the fifth position (and will dispute the Europe League next season), instead of the eighth theoretical position obtained according to this study. It is necessary to mention the value of this team, the youngest one and the one that belongs to the smallest locality, and still has been placing in positions very acceptable in recent years, even to be at the gates of a Champions League final in 2006. In third place is the Real Sociedad, who was placed sixth instead of seventh as predicted this study. A fantastic group of players, led by a coach who knew how to squeeze them to the fullest, managed to put themselves in positions to dispute the Europe league directly and not go through previous rounds, which would have happened if they had been seventh. Finally in this first group is positioned Espanyol, who could situate 8th instead of 10th as envisaged the theory. Despite not getting the European seat, Espanyol season is very dignified, and everything despite not having too much support of his fans as it can be checked in the corresponding dimension.

Table 3. Comparison with reality.

\begin{tabular}{lclc}
\hline $\begin{array}{l}\text { Theoretical } \\
\text { classification }\end{array}$ & Position & Real classification & Position \\
\hline Real Madrid & 1 & Real Madrid & 1 \\
FC Barcelona & 2 & FC Barcelona & 2 \\
Atlético de Madrid & 3 & Atlético de Madrid & 3 \\
Athletic de Bilbao & 4 & Sevilla & 4 \\
Sevilla & 5 & Villarreal & 5 \\
Valencia & 6 & Real Sociedad & 6 \\
Real Sociedad & 7 & Athletic de Bilbao & 7 \\
Villarreal & 8 & RCD Espanyol & 8 \\
Real Betis & 9 & Valencia & 12 \\
RCD Espanyol & 10 & Real Betis & 15 \\
\hline
\end{tabular}


In the group that have obtained the results expected are the three teams that today make the difference in Spanish football. Real Madrid obtained the title of champion after several years of drought in terms of national titles. If you look at the spider diagram of Figure 1, it is verified that Real Madrid is the winner in three of the five classifications, being in second position in the remaining two, so it is not surprising that the results obtained are very positive. Barcelona, the team that has won more league titles in the last decade, was placed in second position, according to what was expected if the theory of this study is attended. In spite of dominating the economic classification, this club did not know how to take advantage of this advantage and therefore it was surpassed by Real Madrid. Atlético de Madrid was in the expected third place, fighting the league until the last days with the previous two teams, something that is not surprising in recent seasons, as the results and the competitiveness of this team have been excellent. It can be said that Atlético de Madrid takes advantage of the resources that it has to the maximum, and, by the hand of its coach, that has managed to lift the spirit of this team, classified to Champions League directly together with the two previous teams, thus avoiding to play the previous round of that competition, which is disputed at the end of July.

In the third and last group, the teams that have worsened the expectations that were assumed, are Athletic de Bilbao, Valencia and Real Betis. Particularly noteworthy are two cases. The first case is Athletic de Bilbaós, a team that as it can be been seen theoretically, it would be able to occupy the fourth place and compete the previous round of the Champions League. These bad results could be due to a deficit of economy with respect to its more immediate competitors and to the policy of the club, which only hires players of the Basque Country as previously mentioned. Moreover, in quality it is also inferior to its competitors, being this another of the reasons why the results have been worse. The second case to be highlighted is Valencia's, an historically team, with the potential to occupy at least the 6th position, and last season saw how it stood in the 12th against all odds. The bad results that were occurring made the top leaders constantly changing coaches, something that could be detrimental to the players because the way of playing was not very clear. In addition, the team was flirting with the descent for much of the season, and consequently, the fans showed its discomfort in a massive way with the team, generating discomfort and insecurity in the players. Last and also relevant was the position that Betis got, occupying the 15th place in front of the ninth that is predicted in this study. Despite having loyal fans, lack of quality and obtaining worse than expected results made the team near to descend to the second Spanish division. Fortunately it kept the category and despite being spending low hours is still considered one of the historical and relevant teams in Spanish football.

\section{Limitations}

Although this index has successfully presented another view of ranking teams, it does not mean it has no limitation. The main limitation presented in this index is its temporality and the difficulty of obtaining the information needed for its composition in successive occasions. To the extent that more data becomes available, the index can be included in further analysis, which would improve our understanding of the phenomena. 


\section{Conclusion}

The performance of a team is a very important aspect that has many dimensions. We propose this Performance Index of Football Teams as an instrument to measure the possibilities clubs have to improve their image. Thus, the creation of an index for club comparisons, and to discern differences in a range of factors, should be of great interest to sport research.

The index is a combination of 22 variables in five dimensions: economic, fans-related, historical, team's quality, and season's data. The goal of the formulation of this index was the measurement of a theoretical performance of 10 teams during the 2016/2017 season. We leave out the rest of the teams that were part of the first division due to the little relevance they provide given their poor historic performance and the fact that they have alternated between first and second division.

Results show that Real Madrid, FC Barcelona and Athletic de Madrid are the highest-ranked teams, matching their season's top positions. Additionally, while Sevilla, Villarreal, Real Sociedad and Espanyol exceeded expectations, Athletic de Bilbao, Valencia and Real Betis did not meet their own, compared with their season's position. We also demonstrate that there are significant cross-club differences in the scores assigned to the different dimensions of the index and the real positions of their rankings, indicating several differences.

\section{Disclosure statement}

No potential conflict of interest was reported by the authors.

\section{Funding}

Jorge Rosales-Salas acknowledges Fondecyt, Chile (Grant 11180337).

\section{References}

Audas, R., S. Dobson, and J. Goddard. 2002. "The Impact of Managerial Change on Team Performance in Professional Sports." Journal of Economics and Business 54 (6): 633-650. doi:10.1016/S0148-6195(02)00120-0.

Ballesteros, C. M. 2015. “'Regionalismos en España' [Regionalism in Spain].” Accessed 5 May 2018. http://elblogdecesarmb.blogspot.com.es/2015/10/regionalismos-en-espana.html

Barajas, A. 2004. "Modelo de valoración de clubes de fútbol basado en los factores clave de su negocio [Valuation Model of Football Clubs Based on the Key Factors of Your Business]." MPRA Paper 13158, University Library of Munich, Germany.

Barajas, Á., and L. Crolley. 2009. "A Model to Explain Support in Spanish Football." Accessed 15 November 2017 https://papers.ssrn.com/sol3/papers.cfm?abstract_id=884107

Barajas, A., Fernández-Jardon, C., and Crolley, L. 2005. "Does sports performance influence revenues and economic results in Spanish football?” MPRA Paper No. 3234, University Library of Munich, Germany.

Barros, C., and S. Leach. 2006. "Performance Evaluation of the English Premier Football League with Data Envelopment Analysis." Applied Economics 38 (12): 1449-1458. doi: $10.1080 / 00036840500396574$.

Bellido, H., J. I. Gimenez Nadal, and R. Ortega. 2011. "Measuring Satisfaction of the Unemployed: A Composite Indicator and Policy Implications." Applied Economics Letters 18 (17): 1687-1690. doi:10.1080/13504851.2011.558475. 
Boulier, B. L., and H. O. Stekler. 2003. "Predicting the Outcomes of National Football League Games." International Journal of Forecasting 19 (2): 257-270. doi:10.1016/S0169-2070(01)00144-3.

Boscá, J., V. Liern, A. Martinez, and R. Sala. 2009. "Increasing Offensive or Defensive Efficiency? an Analysis of Italian and Spanish Football." Omega 37 (1): 63-78. doi:10.1016/j.omega.2006.08.002.

Buraimo, B., and R. Simmons. 2009. "Market Size and Attendance in English Premier League Football." International Journal of Sport Management and Marketing 6 (2): 200-214. doi:10.1504/ IJSMM.2009.028802.

Busto, A. L. 2014. "Los factores explicativos de los resultados económicos de los clubes de fútbol al final de temporada [The explanatory factors of the economic results of the football clubs at the end of the season]." (Unpublished Doctoral thesis). Universidad de Castilla- La Mancha. Toledo.

Cano, J. J. 2015. "Impacto socio-económico del fútbol profesional en España [Socio-economic impact of professional football in Spain]." Accessed 5 May 2018. https://home.kpmg.com/es/es/ home/tendencias/2015/05/impacto-socio-economico-futbol-profesional-espana.html

Christina, R., J. Barresi, and P. Shaffner. 1990. "The Development of Response Selection Accuracy in a Football Linebacker Using Video Training." The Sport Psychologist 4 (1): 11-17. doi:10.1123/ tsp.4.1.11.

Colina, C. L., and P. López Roldán. 1991. "El Análisis de Componentes Principales:aplicación al Análisis de Datos Secundarios [The Analysis of Main Components: application to Secondary Data Analysis]." Papers Revista de Sociologia 37: 31-63. doi:10.5565/rev/papers/v37n0.1595.

Ceballos-Cún, A. S. 2017. "El aspecto disciplinario y su incidencia en el rendimiento deportivo, psicologico y competitivo del futbolista [The Disciplinary Aspect and Its Impact on the Sports, Psychological and Competitive Performance of the Player]." (Unpublished Bachelor thesis), Universidad Técnica de Machala, Ecuador.

Di Betta, P., and C. Amenta. 2010. "A Die-Hard Aristocracy: Competitive Balance in Italian Soccer 1929-2009." Rivista Diritto ed Economia Dello Sport 6 (2): 13-39. https://ssrn.com/ abstract $=1975723$

Escondrillas, C. M. M. 2016. “Análisis económico del fútbol profesional [Economic Analysis of Professional Football]." (Unpublished Bachelor thesis), Universidad Politécnica de Cartagena, Spain.

Fernandez-Crehuet, J. M., J. I. Gimenez Nadal, and L. E. Reyes Recio. 2016. "The National WorkLife Balance Index: The European Case." Social Indicators Research 128 (1): 1-19. doi:10.1007/ s11205-015-1034-2.

Fernandez-Crehuet, J. M., J. I. Gimenez-Nadal, and I. D. del Valle. 2017. "The International Multidimensional Fertility Index: The European Case." Social Indicators Research 132 (3): 13311358. doi:10.1007/s11205-016-1341-2.

Filmer, D., and L. Pritchett. 2001. "Estimating Wealth Effects without Expenditure Data-Or Tears: An Application to Educational Enrollments in States of India." Demography 38 (1): 115-132. doi: $10.2307 / 3088292$.

Gómez, M. Á., M. Gòmez, and S. Jimenez. 2013. "Diferencias Entre Equipos Ganadores y Perdedores de Fútbol en Función Del Tipo de Partido Mediante el Estudio de Indicadores de Rendimiento [Differences between Winning Teams and Football Losers Depending on the Type of Match by Studying Performance Indicators]." Revista Euroamericana de Ciencias Del Deporte 2 (1): 1-5. doi:10.6018/185731.

Gómez, S., and Opazo, M. 2007. "Características estructurales de un club de fútbol profesional de elite [Structural Characteristics of An Elite Professional Football Club]." CSBM - Center for Sport Business Management, DI-705. September 2007. https://media.iese.edu/research/pdfs/ DI-0705.pdf

Gonzalez-Gomez, F., and A. Picazo-Tadeo. 2009. "Can We Be Satisfied with Our Football Team? Evidence from Spanish Professional Football.” Journal of Sports Economics 11 (4): 418-442. doi: $10.1177 / 1527002509341020$.

Hernández, F. A. 2006. "Nuevos planteamientos estratégicos en la gestión de las sociedades anónimas deportivas y clubes de fútbol: propuesta de un modelo de retribución [New Strategic Approaches in the Management of Sports Corporations and Football Clubs: Proposal for a Remuneration Model]." (Unpublished Doctoral thesis), Universidad Autónoma de Madrid. Spain. 
Inglis, S., K. Danylchuk, and D. Pastore. 1996. "Understanding Retention Factors in Coaching and Athletic Management Positions." Journal of Sport Management 10 (3): 237-249. doi:10.1123/ jsm.10.3.237.

Jemmali, H., and C. A. Sullivan. 2014. "Multidimensional Analysis of Water Poverty in MENA Region: An Empirical Comparison with Physical Indicators." Social Indicators Research 115 (1): 253-277. doi:10.1007/s11205-012-0218-2.

Jiménez, J. M. 2013. "Análisis de los indicadores del rendimiento competitivo en goalball [Analysis of competitive Performance Indicators in Goalball]." (Unpublished Doctoral thesis), Universidad de Extremadura, Spain.

Krishnakumar, J., and A. L. Nagar. 2008. "On Exact Statistical Properties of Multidimensional Indices Based on Principal Components, Factor Analysis, MIMIC and Structural Equation Models." Social Indicators Research 86 (3): 481-496. doi:10.1007/s11205-007-9181-8.

Lai, D. 2000. "Temporal Analysis of Human Development Indicators: Principal Components Approach." Social Indicators Research 51 (3):331-366. [Mismatch] doi:10.1023/A:1007065804509.

Lai, D. 2003. "Principal Component Analysis on Human Development Indicators in China." Social Indicators Research 61 (3): 319-330. doi:10.1023/A:1021951302937.

LaLiga. 2017. "Sphera_Sports." Accessed 17 October 2017. http://www.spherasports.com/datosde-asistencia-en-la-liga-2016-17-134864/

Lledó, E., and F. Huertas. 2012. "Perfil Del Técnico de Fútbol en Escuelas de Clubes de Primera División en la Comunitat Valenciana [Profile of the Football Coach in First Division Club Academies in the Region of Valencia]." Apuntes de Educación Física y Deportes 108 (2): 35-45. http://www.revista-apunts.com/es/hemeroteca?article $=1540$

Marcos, A. S. 2016. "Investigación de mercados sobre las diferencias entre los aficionados al futbol en la liga española [Market Research on the Differences Between Soccer Fans in the Spanish League]." (Unpublished Bachelor thesis), Universidad de Cantabria, Spain.

OECD. 2008. Handbook on Constructing Composite Indicators. Metodology and User Guide. 1 ed. París: OECD Publications.

Pastore, D., and W. Meacci. 1994. "Employment Process for NCAA Female Coaches." Journal of Sport Management 8 (2): 115-128. doi:10.1123/jsm.8.2.115.

Pérez-González, B. 2017. "La Resistencia a la Regresión a la Media. El Caso Del Atlético de Madrid, Campeón en Eficiencia Económica Desde 2014 [the Resistance to Regression toward the Mean. The Case of Atlético de Madrid, Leader in Economic Efficiency since 2014]." Journal of Sport and Health Research 9 (3): 357-368. https://dialnet.unirioja.es/servlet/articulo?codigo $=6350037$

Reina-Gomez, A., and A. Hernández-Mendo. 2012. "Revisión de Indicadores de Rendimiento en Fútbol [Football Performance Indicators Review]." Revista Iberoamericana de Ciencias de la Actividad Física y el Deporte 1 (1): 1-14. http://www.riccafd.uma.es/DOCUMENTOS/articulos/ VOL001/N1/alvaritomendo.pdf

Rendón, N. J. F. 2012. "Determinantes del desempeño deportivo y de los ingresos de los equipos profesionales de fútbol de Colombia [Determinants of Sports Performance and Income of the Professional Soccer Teams of Colombia]." Unpublished Master thesis, Universidad Santo Tomás, Colombia.

Robles, F. L.-C. 2015. "Como afecta el patrocinio deportivo en los ingresos y en los resultados de los clubes de fútbol [How Sports Sponsorship Affects the Income and Results of Football Clubs]." Unpublished Bachelor thesis, Universidad Politécnica de Cartagena, Spain.

Soriano, M. Á. S. 2005. "Resistencia general y específica en un equipo de fútbol [General and Specific Resistance in a Football Club]." Unpublished Bachelor thesis, Universidad Autónoma de Madrid, Spain.

Statista. 2019. "Income From Television Rights in the Spanish Football League (La Liga) in the 2016/2017 Season, by Team (in Million Euros).” https://www.statista.com/statistics/782317/ la-liga-tv-rights-revenue-received-by-football-teams-in-spain/

Staurowsky, E., B. Parkhouse, and M. Sachs. 1996. "Developing an Instrument to Measure Athletic Donor Behavior and Motivation." Journal of Sport Management 10 (3): 262-277. doi:10.1123/ jsm.10.3.262.

Szymanski, S., and T. Kuypers. 1999. Winners and Losers: The Business Strategy of Football. Harmondsworth: Penguin. 